\title{
Impact of same-day appointments on patient satisfaction with general practice appointment systems
}

Fiona Sampson, Mark Pickin, Alicia O'Cathain, Stephen Goodall and Chris Salisbury

\begin{abstract}
Following recent concerns about patients' inability to book appointments in advance, this study examined the relationship between the proportion of GP appointments reserved for same-day booking, and patient satisfaction with appointment systems. In a survey of 12825 patients in 47 practices, it was found that a $10 \%$ increase in the proportion of same-day appointments was associated with an $8 \%$ reduction in the proportion of patients satisfied. Practices should be wary of increasing the level of same-day appointments to meet access targets.

Keywords

appointments and schedules; family practice; health services accessibility; patient satisfaction; primary health care.
\end{abstract}

\section{INTRODUCTION}

Recent policy initiatives related to government targets for primary care access in The NHS Plan, ${ }^{1}$ such as Advanced Access, ${ }^{2}$ have led to changes in the numbers of appointments that are reserved for patients booking on the day (same-day appointments). ${ }^{3}$ This has led to high-profile criticisms that patients are less able to book appointments in advance, ${ }^{4,5}$ a particular concern for certain groups such as older patients, ${ }^{6}$ and those with chronic conditions. ${ }^{6-8}$ There is also uncertainty about whether the success of these initiatives is related to the level of deprivation of the practice population. ${ }^{7}$ A recent evaluation of Advanced Access showed no difference in patient satisfaction with the appointment system between Advanced Access and control practices. ${ }^{9}$ However, there was considerable overlap between initiatives used by Advanced Access and control practices. ${ }^{3}$ Since difficulties in booking appointments in advance have been a focus of concern, ${ }^{4}$ this study has examined the relationship between the proportion of GP appointments reserved for the same day and patient satisfaction with appointment systems, regardless of practices' Advance Access status.

\section{METHOD}

Data from the recent evaluation of Advanced Access were used, described in detail elsewhere. ${ }^{10}$ The data were a comparison of 48 general practices selected from 12 primary care trusts (PCTs) in England. The study made use of two components of this evaluation: a survey of practices and a survey of patients. The survey of practices undertaken in 2004 involved 391 practices from 12 PCTs purposefully selected to be representative of England. ${ }^{3}$ This provided data on the numbers of GP appointments offered in each practice, both bookable in advance and same-day only. The patient survey involved 12825 adult patients attending 47 of the practices, undertaken in $2005 .{ }^{9}$ This provided data on patient satisfaction with the practice appointment system.

\section{Analysis}

Responses to a question about 'overall satisfaction with the appointment system', which had been 


\section{How this fits in}

Recent policy initiatives related to government targets for primary care access

have led to changes in the numbers of appointments that are reserved for patients booking on the day. There has been concern about difficulties with booking appointments in advance. This study found that increasing the proportion of sameday GP appointments was associated with a reduction in patient satisfaction with appointment systems, particularly in older patients. Practices should be wary of increasing the level of same-day appointments to meet access targets.

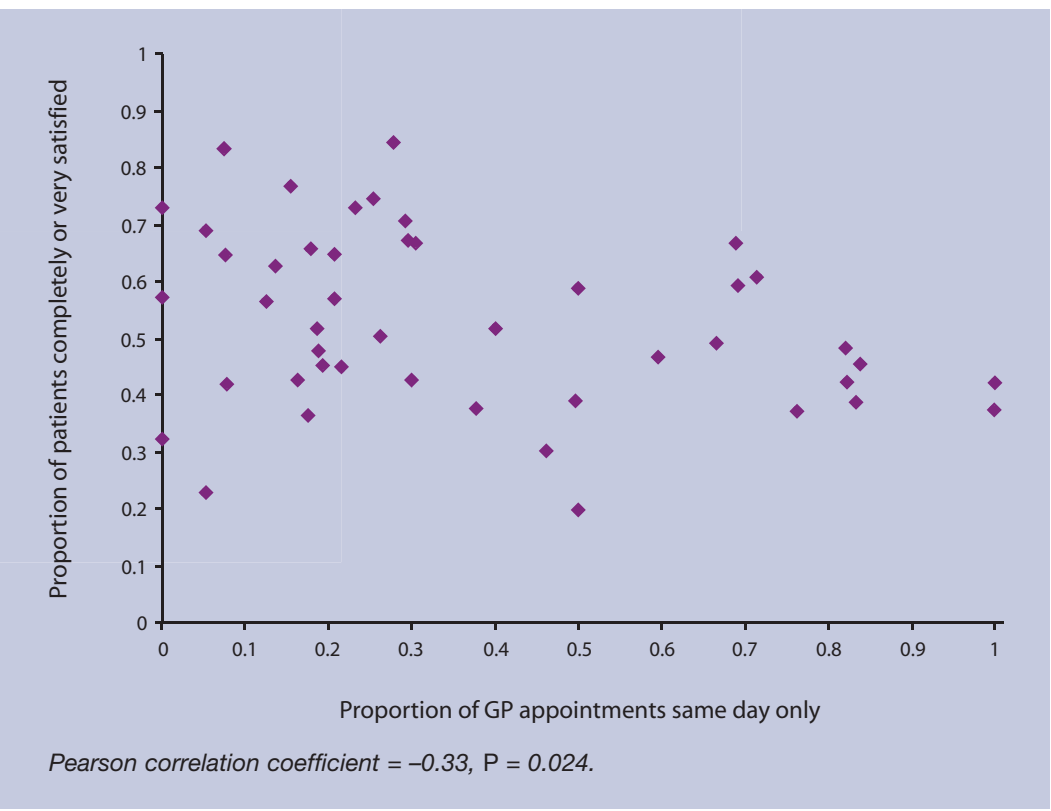

Figure 1. Relationship between patient satisfaction with GP appointment systems and proportion of same-day appointments by practice. answered on a 7-point Likert scale, were dichotomised to 'completely and very satisfied' versus all other categories. This was the dependent variable in a multilevel logistic regression undertaken using the XTLOGIT command in STATA (version 9.2). The proportion of same-day appointments was grouped into units of 10 and treated as a continuous variable. The effect of the proportion of same-day GP appointments was tested, adjusted for potential confounding factors at the practice level (number of GP appointments offered in total by the practice per 1000 population, training practice or not, receiving deprivation payments or not, previously been

\section{Table 1. Relationship between proportion of same-day appointments and patient satisfaction with appointment systems.}

\begin{tabular}{lcccc} 
Variable & UOR & AOR & $95 \% \mathrm{Cl}$ & $P$-value \\
\hline Proportion of same-day GP appointments & 0.91 & 0.92 & 0.90 to 0.94 & 0.001 \\
\hline $\begin{array}{l}\text { Interaction between proportion of same-day } \\
\text { GP appointments and: }\end{array}$ & & & \\
$\quad$ older patients & 0.93 & 0.90 to 0.96 & 0.001 \\
chronic conditions & 0.97 & 0.95 to 1.00 & 0.100 \\
deprivation payments & 1.18 & 1.12 to 1.24 & 0.001 \\
\hline
\end{tabular}

$A O R=$ adjusted odds ratio. $U O R=$ unadjusted odds ratio. fundholders or not, and list size), and at the patient level (age, sex, chronic illness status, and ethnicity). Interaction terms between the proportion of same-day GP appointments and being older, having a chronic condition (defined as reported longstanding illness, disability, or infirmity) and practice in receipt of deprivation payments were tested to determine whether the acceptable balance of same-day and booked in advance appointments differed by type of patient or practice.

\section{RESULTS}

The overall response rate to the patient survey was 84\% ( $n=10821$ received from 12825 questionnaires sent out). The question about satisfaction with the practice appointment system was completed by 10547 patients. Patient and practice characteristics are reported in detail elsewhere. ${ }^{10}$ Overall, 52\% (5490/10 547, range $20-84 \%)$ of patients were completely or very satisfied with the appointment system at their practice. Among practices, the mean proportion of same-day appointments with a GP was $36 \%$ (range $0-100 \%$ ). Practices mainly offered $30 \%$ or less of their appointments as same-day (28/47), with one-quarter offering over $50 \%$ of appointments as same-day (12/47). There was a negative correlation between the proportion of same-day appointments and patient satisfaction for the 47 practices (Figure 1). The mean proportion of patients completely or very satisfied with their appointment system was $58 \%$ for practices with less than $30 \%$ of same-day appointments, compared with $48 \%$ for practices with more than $50 \%$ of same-day appointments. Using multilevel modelling, there was an inverse relationship between the proportion of same-day appointments and the proportion of patients who were completely or very satisfied with their practice's appointment system. For each $10 \%$ increase in same-day appointments, there was an $8 \%$ reduction in satisfaction, adjusted odds ratio $=0.92(95 \%$ confidence interval $=0.90$ to 0.94 ). This relationship was more marked for older people (aged $\geq 65$ years), and in practices that were not in receipt of deprivation payments (Table 1 ).

\section{DISCUSSION}

\section{Summary of main findings}

It was found that increasing the proportion of sameday GP appointments leads to a reduction in patient satisfaction with appointment systems, particularly in older patients. It was also more pronounced in lessdeprived practices, suggesting that the ability to book appointments in advance is particularly valued in practices serving more affluent populations. The findings support previous concerns that the benefits of increasing same-day GP appointments for some 
groups of patients may be outweighed by the difficulties in booking appointments in advance experienced by other groups of patients.,6-8

\section{Strengths and limitations of the study}

This study is the first to examine the impact of sameday appointments on patient satisfaction with appointment systems from a national sample of practices. The data on satisfaction with appointment systems is based on a survey of over 12000 patients with a high response rate, although the information was obtained from a single item only. A limitation is that the analysis was restricted to appointments that could be booked, whether on the day only or in advance. It excluded 'unscheduled' consultations, such as open surgeries where patients could attend without appointments, and 'extras' seen at the end of surgery. However these consultations without appointments represented less than $7 \%$ of all consultations in the study, and when they were included in the analysis the findings were not affected.

\section{Comparison with existing literature}

Previous research suggests that younger people, ${ }^{11}$ and patients in deprived areas, ${ }^{12,13}$ are more likely to use same-day appointments, which is in line with the present findings. The relationship between the present findings and some other studies is less clear. Satisfaction has been found to be higher in practices with a high rate of appointments available at the start of the working day, ${ }^{14}$ and a recent study found that patients using same-day care were likely to be in work and have a higher educational status. ${ }^{11}$ The study's findings are compatible with others that advocate a combined appointment system, allowing both prebookable and same-day appointments, noting that different patient groups have differing requirements..$^{11,15}$

\section{Implications for clinical practice}

This study is particularly pertinent as access to primary care returns to centre stage in government health policy. ${ }^{16}$ Attempts to improve access must be based on evidence if the Department of Health is to avoid criticism for rolling out initiatives prior to independent evaluation..$^{17,18}$ In particular, practices should be wary of increasing the level of same-day appointments to meet access targets, and need to get the balance between pre-bookable and same-day appointments right for their particular patients, to optimise satisfaction. Although patients value speed of access, other factors, such as being able to book appointments in advance with a chosen doctor, must not be sacrificed for marginal gains in what are already fast access times in the UK in comparison with other countries. ${ }^{16,19}$

\section{Funding body}

This article presents independent research commissioned by the National Institute for Health Research (NIHR) Service Delivery and Organisation (SDO) Programme. The views expressed in this publication are those of the authors and not necessarily those of the NHS, the NIHR or the Department of Health. The NIHR SDO programme is funded by the Department of Health (SDO/70/2004)

\section{Ethical approval}

Thames Valley Multicentre Research Ethics Committee (MREC 04/12/024)

\section{Competing interests}

The authors have stated that there are none

\section{Acknowledgements}

We would like to thank all the patients and practice staff who contributed to this study and also the other members of the Advanced Access Evaluation Team: Jon Banks, Helen Baxter, Alan Montgomery, Mary Wallace (University of Bristol), Lucy Simons, Karen Gerard, Val Lattimer, Catherine Pope (University of Southampton), Sarah Edwards, Helen Smith (University of Brighton), and Markella Boudioni (London South Bank University). We would also like to thank Alan Montgomery and Mike Bradburn for statistical advice.

\section{Discuss this article}

Contribute and read comments about this article on the Discussion Forum: http://www.rcgp.org.uk/bjgp-discuss

\section{REFERENCES}

1. Department of Health. The NHS plan. A plan for investment, a plan for reform. London: Department of Health, 2000.

2. Oldham J. Advanced Access in primary care. Manchester: National Primary Care Development Team, 2001.

3. Goodall S, Montgomery A, Banks J, et al. Implementation of Advanced Access in general practice: postal survey of practices. $\mathrm{Br} \mathrm{J}$ Gen Pract 2006; 56(533): 918-923.

4. BBC News. Patients denied advanced bookings. http://news.bbc.co.uk/ 1/hi/health/4112390.stm (accessed 28 Apr 2008).

5. BBC News. 48-hour target 'damaging GP care'. http:// news.bbc.co.uk/1/hi/health/3682920.stm (accessed 28 Apr 2008)

6. Pickin M, O'Cathain A, Sampson FC, Dixon S. Evaluation of Advanced Access in the National Primary Care Collaborative. $\mathrm{Br} \mathrm{J}$ Gen Pract 2004; 54(502): 334-340

7. Dixon S, Sampson F, O'Cathain A, Pickin DM. Advanced access: more than just GP waiting times? Fam Pract 2006; 23(2): 233-239.

8. Windridge K, Tarrant C, Freeman GK, et al. Problems with a 'target' approach to access in primary care: a qualitative study. Br J Gen Pract 2004; 54(502): 364-366.

9. Salisbury C, Goodall S, Montgomery AA, et al. Does Advanced Access improve access to primary health care? Questionnaire survey of patients. Br J Gen Pract 2007; 57(541): 615-621

10. Salisbury C, Banks J, Goodall S, et al. An evaluation of Advanced Access in general practice. http://www.sdo.lshtm.ac.uk/ sdo702003.html (accessed 28 Apr 2008).

11. Stoddart H, Evans M, Peters TJ, Salisbury C. The provision of 'sameday' care in general practice: an observational study. Fam Pract 2003; 20(1): 41-47.

12. Taylor B. Patient use of a mixed appointment system in an urban practice. BMJ 1984; 289(6454): 1277-1280.

13. Virji A. A study of patients attending without appointments in an urban general practice. $B M J$ 1990; 301(6742): 22-26.

14. Campbell JL. General practitioner appointment systems, patient satisfaction, and use of accident and emergency services - a study in one geographical area. Fam Pract 1994; 11(4): 438-445

15. Pascoe SW, Neal RD, Allgar VL. Open-access versus bookable appointment systems: survey of patients attending appointments with general practitioners. Br J Gen Pract 2004; 54(502): 367-369.

16. Campbell J. Access to primary care: advanced ... or smart? Br J Gen Pract 2007; 57(541): 603-604.

17. Salisbury C. Does Advanced Access work for patients and practices? Br J Gen Pract 2004; 54(502): 330-331

18. McDonnell A, Wilson R, Goodacre S. Evaluating and implementing new services. BMJ 2006; 332(7533): 109-112

19. Pope C, Banks J, Lattimer V, Salisbury C. Improving access to primary care: eight case studies of introducing Advanced Access in England. J Health Serv Res Pol 2008; 13(1): 33-39. 